\title{
Research on Safety of Mine Power Supply System
}

\author{
Chen Weihua ${ }^{1,2^{*}}$, Shan Renzhong ${ }^{1,2}$, Bai Cuifen ${ }^{1,2}$, and Zhang Youdong ${ }^{1,2}$ \\ ${ }^{1}$ School of Mechanical and Electrical Engineering, North China Institute of Science and Technology, China \\ ${ }^{2}$ Hebei Key Laboratory of Safety Monitoring of Mining Equipment, North China Institute of Science and Technology, China
}

\begin{abstract}
Electric power is one of the main supplies of mine energy. The safety of electric power is of great significance to the safety of mines. The probability of blackout is relatively small. But once it happens, the harm is great. In order to improve the safety of mine power supply, this paper summarizes the research on the safety of mine power supply system, puts forward the research direction, and prospects the development of mine power security in the future.
\end{abstract}

\section{Introduction}

Stable power supply is one of the important conditions for the normal operation of mines. In recent years, the power grid is gradually becoming interconnected and giant. The dispatching level of power grid operation is improving year by year, the reliability of power grid equipment is gradually improving, and the scale of power grid is gradually expanding. A single common fault is difficult to cause greater risk pressure on the overall safe and stable operation of power grid. However, in recent years, it should be noted that the frequency of blackout disasters in domestic and foreign mines has shown an upward trend, which has brought great impact on the normal operation of mines. At present, mine power supply system security research has become one of the hot spots.

The electricity supply industry has been shifting from a regulated system to competitive and uncertain market environment. The organizational unbinding of supply, transmission, distribution and system operation has resulted in more highly stressed and unpredictable operating conditions. The introduction of competitive supply and the interconnection of grids may often result in long distance transmission usage. This may depress bus voltage magnitudes and endanger power system security. Recent blackout failures in several power systems worldwide require urgent and thorough attention.

A mine is a place for mining ore or producing mineral raw materials. Mining is a high risk industry. We must pay attention to safety in production. In view of various hazardous factors, the mine should formulate corresponding safety precautions. Corresponding accident emergency mechanism should be established, so as to ensure timely treatment after accidents and reduce personal and property losses. The occurrence conditions of coal seams are complex. The mining is difficult. And the factors that affect the safety production are the objective causes of frequent accidents. In the past, coal industry still followed the traditional safety inspection methods. Some safety inspectors only relied on experience and sense of responsibility to conduct onsite inspection and lacked quantifiable monitoring scheme. The rights and responsibilities of safety supervision personnel are confused. They are not standardized. The safety of coal mine workers cannot be guaranteed.

The safety management of coal mine industry in the past is mostly traditional. Modern scientific management were lack. Traditional management is often "experiential" and "ex post" management. It pays too much attention to experience. The experience is used to summarizing and improving afterwards. Basically, it adopts the procedures of planning, arrangement, inspection, summary and evaluation. But modern coal mine safety management needs advanced scientific management methods. The prominent feature of modern occupational safety and health management is systematic management. The inevitable trend of coal mine production and development is intrinsic safety. The intrinsic safety management system of coal mine should be established. The potential dangers and harmful factors should be found out. Relevant countermeasures should be formulated to eliminate the sources of danger. The safety and economy of production should be ensured. Making people, things, systems and systems safe and harmonious operation. So as to realize the safety goal of no defects in system, no loopholes in management, zero defects in equipment and no accidents. The safety production of coal mine should be realized. We should further improve the laws and regulations of safety production supervision. A strong occupational safety supervision system should be established to realize the stable improvement of coal mine safety production.

This paper summarizes the research on the safety of mine power supply system. Through the study of emergency dispatching, the harm of mine blackout disaster can be effectively prevented and reduced, and the power supply can be restored in time to ensure the normal operation of the mine.

\footnotetext{
* Corresponding author: cwhwc@163.com
} 


\section{Characteristics of mine electric power accidents}

The probability of mine blackout is small, but once the power grid blackout, the consequences are very serious. First, once an accident occurs in a mine, it often involves the life safety of personnel. Second, it has a wide range of influence and great economic losses. Third, the mine blackout accidents are often caused by other natural disasters, such as extreme heat, cold, strong wind, rainstorm, earthquake and so on. If the mine can not restore the power supply in time, it will hinder the disaster relief work of the mine.

Finally, in the state of war, we should guard against the enemy's strike mode of mine blackout.

\section{Main research areas}

At present, more and more attention has been paid to the research of blackout disaster. The research focuses on the construction of power grid model, power grid simulation, power grid evaluation index, power grid accident prevention and response measures and other fields.

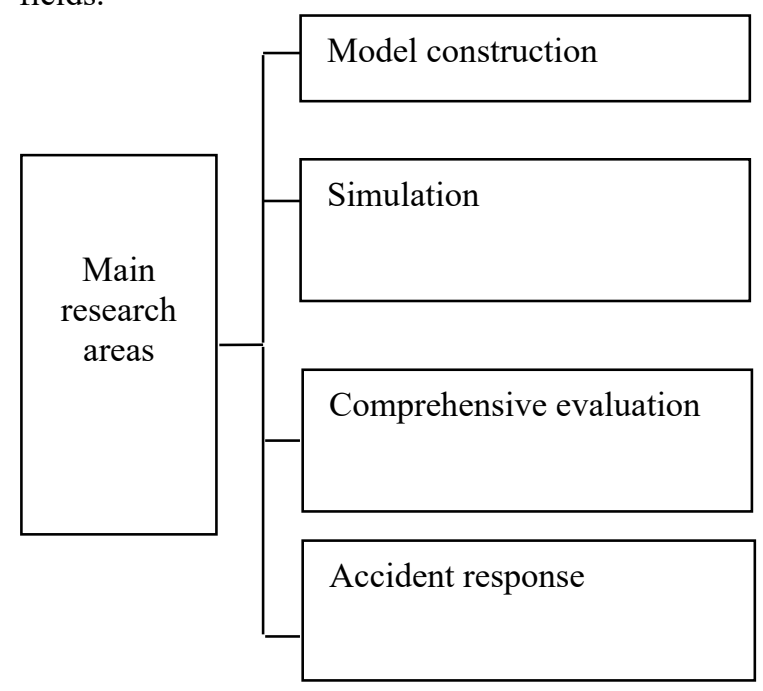

Fig. 1. Main research areas

\subsection{Model construction}

In the aspect of power grid model construction, reference [1] analyzes multi energy flow network modeling from two aspects of multi energy coordinated operation and distributed coordinated regulation. In reference [2], conditional value at risk (CVR) theory is introduced into the operation scheduling problem of multi energy flow system, and an economic scheduling simulation model considering the uncertainty of wind, light output, power and heat load is proposed. Reference [3] summarizes the modeling method of air conditioning load and aggregation model. Reference [4,5] divides user load into translatable load, transferable load and reducible load, and establishes relevant models to participate in the economic dispatch of microgrid. Although these models can not reflect the demand response characteristics of the resource scheduling model, they are not easy to solve. However, the research object and means are relatively single, and most of the energy models analyzed are classical systems, which are not universal and difficult to be popularized. When the use conditions are complicated or the use environment is bad, the model needs to be adjusted in time to adapt to the corresponding situation and maximize the energy utilization.

\subsection{Simulation}

In recent years, the development of simulation, communication, control and power grid in Europe is discussed. Reference [6] analyzes the key factors affecting the adaptability of renewable energy in power grid, discusses the adaptive technology, integrated energy system and market consumption in power grid. Reference [7] summarizes the development process of power grid simulation in recent years, and affirms its contribution. Reference [8] discusses the development prospect of power grid simulation. Reference [9] discusses the application of power grid simulation technology in multi energy system. Reference [10] affirms the role of simulation in the system and illustrates its application value with examples. Reference [11] studies different power grid simulation technologies A quasi steady state multi energy flow analysis model is proposed and calculated. In reference [12], an uncertain grid model considering multiple time scales is constructed, and the simulation model is used to analyze the microgrid system including wind turbines and cogeneration. The above simulation models are all for local or small system simulation. However, the system model cannot be built in the global perspective. The model cannot adapt to the current large-scale dispatching and power demand of the power industry. The model need to be further improved.

\subsection{Comprehensive evaluation}

In the aspect of comprehensive evaluation index of power grid, in reference [13], starting from the basic process of power grid planning and construction, an evaluation index system is established according to the five evaluation angles of economy, energy, environment, society and engineering. The indexes are analyzed quantitatively and qualitatively. In the comprehensive evaluation method of power grid, how to determine a reasonable evaluation method according to the characteristics of power grid is the key research direction in the field of electric power. At present, the commonly used evaluation methods can be divided into subjective qualitative evaluation method, multivariate statistical analysis method and system analysis based method [14]. In related fields, some experts and scholars combine a variety of evaluation methods and put forward more specific evaluation methods, mainly including the evaluation method based on ahp-dea model, the evaluation method based on improved genetic algorithm and the evaluation method based on ahp-x weight method [15]. The evaluation methods in the above 
reference need to consider too many interference factors, which are greatly affected by the system and external factors, and the operation conditions are very strange. Once the use environment changes, it is difficult to get accurate evaluation results, and the stability and accuracy need to be further improved.

\subsection{Accident response}

In the aspect of power grid accident response, the paper analyzes the "8.14" Blackout Accident of American and Canadian in reference [16], and summarizes the lessons to be learned. The paper analyzes the "11.4" blackout in Western Europe in document [17], and puts forward some suggestions for the safe operation of central China power grid. The paper analyzes the power outage in India and points out the development direction of the key technologies in the future of smart grid construction under the background of system security. The paper studies the "2.4" blackout in Brazil and puts forward the Enlightenment of safe and stable operation of power grid. The paper studies the power grid accidents in China in the reference [18], and focuses on the analysis of the impact of new energy grid connection on the safe operation of the power grid. The research of the abovementioned documents is mainly the research of the power grid accidents. On this basis, the paper puts forward the relevant enlightenment or suggestions on the safe operation of the power grid, isolated the power grid, and lacks the coordination with other systems from the perspective of emergency rescue.

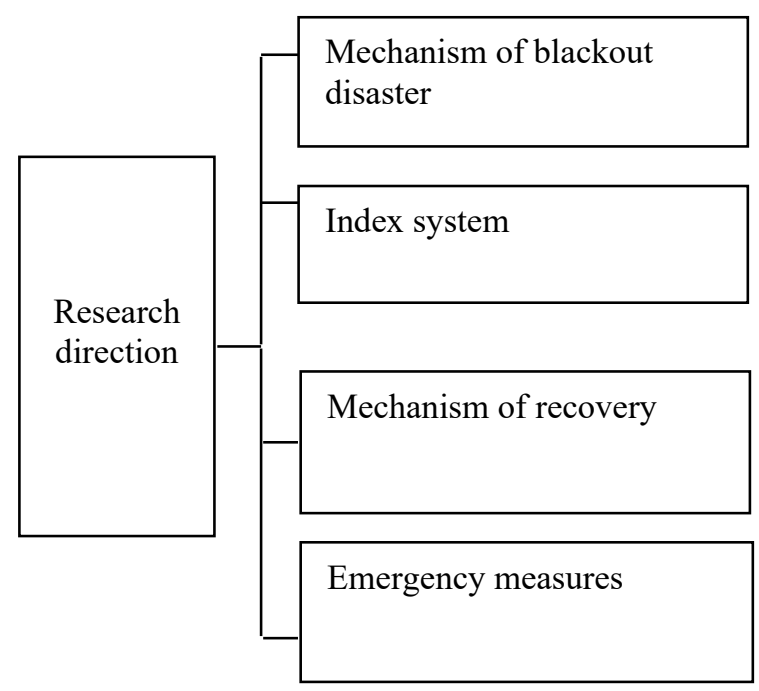

Fig. 2. Research direction

\section{Research direction}

\subsection{Mechanism of blackout disaster}

The blackout disasters at home and abroad in recent years should be summarized. The mechanism of blackout disasters should be studied. And the inducement, development process and consequences of blackout accidents should be analysed. The interaction between blackout disaster and other disasters is studied.
In the aspect of environment, it studies all kinds of accidental events caused by uncertain and uncontrollable factors in the environment. In the aspect of power grid operation, the influence and harm of harmonic, impact load and air conditioning load in power grid are studied. In the electricity market, the influence of market power and speculation factors is studied.

\subsection{Index system}

Based on the risk theory, a set of risk assessment and prevention system is established to effectively evaluate the security level of power grid, to give early warning to the potential risks threatening the safe and stable operation of power grid, and to give corresponding correction methods, so as to provide strong decision support for the operation and dispatching personnel. It plays the role of optimizing the safe operation of the system, strengthening the ability of power grid defense against various risks, and improving the level of security management. At the same time, through the analysis of power grid structure risk, it can also play a corresponding guiding role in the optimal allocation of resources in the power market.

\subsection{Mechanism of recovery}

After the occurrence of blackout disaster, the overall goal is to restore power supply safely and quickly in the case of blackout or partial blackout, so as to minimize the impact of blackout. Study and optimize the power supply recovery process, determine the starting power supply, plan the transmission circuit path and load recovery sequence. This paper studies the interaction between power supply and municipal facilities such as water supply, heating, gas, transportation and telecommunications in the recovery process, so as to minimize the impact on Residents' lives and reduce economic losses.

\subsection{Emergency measures}

The position and role of power emergency dispatch in the overall framework of disaster prevention, mitigation and relief emergency command are clarified. Based on the establishment of power grid operation monitoring index system, the risk prevention measures of blackout are formed. On the basis of the recovery mechanism after blackout, the disaster relief mechanism, measures and process are established.

\section{Conclusion}

It is of great significance to study mine power safety. It is necessary to study the mine power safety from many aspects. Recently, the related models are studied. In the future, we will study the other aspects of mine power safety. Research in this area needs to be strengthened.

In order to improve the safety of mine power supply system, it is necessary to do the following: 
(1) All units should attach great importance to it. A leading group should be established. Organizational leadership should be strengthened. Self-inspection and inspection plans should be formulated. The division of responsibilities should be clarified. And a listing supervision system for major issues and problems should be adopted to ensure that the supervision work is carried out as planned.

(2) All units should strengthen the self-examination and inspection of major projects, important links and high-risk operations. Workers should go deep into the grass-roots front line. The laws should be supervised and enforced strictly. And "zero tolerance" is for the problems. A list of problems should be established to timely supervise and urge the rectification.

(3) The dispatched energy regulatory agencies and the power management departments of local governments should strengthen communication and cooperation. A joint force should be formed to do a good job in supervision.

(4) The supervision work should be practical and realistic. The reality should be reflected comprehensively and objectively, so as to ensure the effectiveness of the supervision work.

\section{Acknowledgements}

The acknowledgements: this paper is supported by the Fundamental Research Funds for the Central Universities (3142020014) and the Fundamental Research Funds for the Central Universities (3142019055).

\section{References}

1. Zhang W, Lian J, Chang C, et al. Aggregated modeling and control of air conditioning loads for demand response. IEEE transactions on power systems, 28, 4655-4664(2013).

2. Steenhof P A. Decomposition of electricity demand in China's industrial sector. Energy Economics, 28, 370-384(2006).

3. Huang A Q, Crow M L, Heydt G T, et al. The Future Renewable Electric Energy Delivery and Management (FREEDM) System: The Energy Internet. Proceedings of the IEEE, 99, 133148(2010).

4. Briguglio L, Nigrelli M, Eichinger F, et al. A marketplace-based approach to demand-side management in the smart grid. ERCIM NEWS, 32, 7-8(2013).

5. Yun Yang, Zhuangzhi Fang, Fanpeng Zeng, et al. Research and prospect of virtual microgrids based on energy internet. 2017 IEEE Conference on Energy Internet and Energy System Integration, 1, 26-28(2017).

6. Jizhong Zhu, Pingping Xie, Peizheng Xuan, et al. Renewable energy consumption technology under energy internet environment. 2017 IEEE Conference on Energy Internet and Energy System Integration, 1, 26-28(2017).

7. Wu Xiao, Ge Beichang, Zang Tianlei, et al. Management system research of large-scale new energy development based on energy internet[J]. 2017 IEEE Conference on Energy Internet and Energy System Integration, 1, 26-28(2017).

8. Chun-Cheng Lin, Der-Jiunn Deng, Wan-Yu Liu, et al. Peak Load Shifting in the Internet of Energy With Energy Trading Among End-Users. IEEE Access, 13,123-133(2017).

9. Xiao J, Bai L, Li F, et al. Sizing of energy storage and diesel generators in an isolated microgrid using discrete Fourier transform (DFT). IEEE Transactions on Sustainable Energy, 5, 907916(2014).

10. Li S, Zhang W, Lian J, et al. Market-based coordination of thermostatically controlled loadsPart I: A mechanism design formulation. IEEE Transactions on Power Systems, 31, 11701178(2016).

11. Hongwen He, Rui Xiong, Hongqiang Guo, Shuchun Li. Comparison study on the battery models used for the energy management of batteries in electric vehicles. Energy Conversion and Management, 64, 35-41(2012).

12. Lu L, Han X, Li J, et al. A review on the key issues for lithium-ion battery management in electric vehicles. Journal of power sources, 226, 272288(2013).

13. Thomas A. Modularized battery management for large lithium ion cells. Journal of Power Sources, 196, 458-464(2011).

14. Jiang J C, Wen F, Wen J P, et al. Battery Management System Used in Electric Vehicles. Power Electronic Technology, 45, 2-10(2011).

15. Jianqiu, Liangfei. Control system design of hybrid fuel cell city bus. Engineering Sciences, 8, 8491(2010).

16. Xing Yinjiao, Eden W. M. Ma, Kwok L. Tsui. Battery Management Systems in Electric and Hybrid Vehicles. Energies, 4, 1845-1849(2011).

17. Chan $\mathrm{C} \mathrm{C}$. The state of the art of electric, hybrid, and fuel cell vehicles. Proceedings of the IEEE, 95, 704-718(2007)

18. Chen, Haisheng, Cong T N, Yang W, et al. Progress in electrical energy storage system: a critical review. Progress in Natural Science, 19, 291-312(2009). 